\title{
Generation of Trichoderma reesei Mutant with Enhanced Xylanase Activity by Using Disparity Mutagenesis
}

\author{
(Received August 18, 2018; Accepted December 8, 2018) \\ (J-STAGE Advance Published Date: January 18, 2019) \\ Taisuke Watanabe, ${ }^{1}$ Masashi Nasukawa, ${ }^{1,2}$ Yuki Yoshida, ${ }^{1}$ Takashi Kogo, ${ }^{1}$ \\ Jun Ogihara, ${ }^{1, \dagger}$ and Takafumi Kasumi ${ }^{1}$ \\ ${ }^{1}$ Applied Microbiology and Biotechnology Laboratory, College of Bioresource Sciences, Nihon University \\ (1866 Kameino, Fujisawa, Kanagawa 252-0880, Japan) \\ ${ }^{2}$ Biotechnology Center, Chitose Laboratory Incorporated \\ (907 Nogawa, Miyamae-ku, Kawasaki, Kanagawa 216-0001, Japan)
}

\begin{abstract}
In the current study, we attempted to enhance the xylanase activity of Trichoderma reesei ATCC66589 by using disparity mutagenesis, wherein a plasmid harboring proofreading-impaired DNA polymerase $\delta$ was inserted. Following selection on xylan-rich media and successive plasmid curing, a mutant showing conidiospores strikingly different from those of the parent strain, with many small humped-surface spheres, was generated. Xylanase and $\beta$-xylosidase activities of the mutant XM1, cultivated in xylan medium, were 15.8- and 11.0-fold higher than those of the parent strain, respectively. Furthermore, xylanase activity was generated approximately $24 \mathrm{~h}$ in advance compared to that in the parent. In contrast, when cultivated in Avicel medium, its xylanase and $\beta$-xylosidase activities were 0.14and 0.33-fold, respectively, compared to those in the parent. Among the xylan component sugars and related polyols, D-xylose and xylobiose exerted a distinct inductive effect on the xylanase activity in Avicel media, while xylitol and L-arabinose did not. Mutagenesis involved in xylose catabolism is suggestive of changes at the gene transcription level. Although the induction mechanism remains unclear in details, disparity mutagenesis may be useful for obtaining $T$. reesei mutants with high xylanase activity.
\end{abstract}

Key words: disparity mutagenesis, xylanase, xylan, Trichoderma reesei ATCC66589, enzyme induction

\section{INTRODUCTION}

The disintegration of plant cell wall polysaccharides into their component sugars prior to fermentation is a process that is crucial for bio-ethanol production from natural, underutilized biomasses, such as wood chips, corn stover, or rice straw. ${ }^{1{ }^{12)}}$ Generally, chemical or enzymatic decomposition of the biomass is used for this purpose. Enzymatic digestion is considered preferable compared to acid or alkaline hydrolysis, since it proceeds under milder conditions, such as room temperature and neutral $\mathrm{pH}$, which prevents excess degradation of the hydrolysate. ${ }^{3)}$ Thirteen million tons, in dry weight, of rice straw is annually produced in Japan as the waste material of rice production. Approximately $30 \%$ of rice straw is utilized as fertilizer or livestock feed. However, the remaining $70 \%$ is discarded, as a huge amount is available each year. Rice straw, which is a potential resource for bio-ethanol production, consists mainly of polysaccharides (cellulose $(30 \%)$ and xylan $(15 \%))$, lignin $(17 \%)$, and ash $\left(18 \%\right.$, mostly as silica). ${ }^{1) 2}$ These polymers crosslink to construct a rigid, intricate

${ }^{\dagger}$ Corresponding author (Tel. \& Fax. +81-466-84-3945,

E-mail: ogihara.jun@nihon-u.ac.jp).

This is an open-access paper distributed under the terms of the Creative Commons Attribution Non-Commercial (by-nc) License (CC-BYNC4.0: https://creativecommons.org/licenses/by-nc/4.0/). three-dimensional structure that inhibits rapid degradation of tissue into its component sugars. The polymers hemicellulosic xylan and lignin surround a micro-fibrous sheaf consisting of crystalline cellulose to protect and fortify the tissue. Due to the specific structure thus formed, effective enzymes with high xylanolytic activity are required to digest rice straw. ${ }^{24) 5}$ )

Trichoderma reesei has been well known to produce large amounts of extracellular enzymes. ${ }^{67)}$ Since most of the excreted proteins consist of various cellulases and hemicellulases, T. reesei is considered one of the most prolific producers of biomass-degrading enzymes. ${ }^{67)(8) 9) 10)} T$. reesei ATCC66589, a strain bred from T. reesei QM6a (Natick, US Army), reportedly accounts for the highest cellulase productivity. Depending on the culture condition, the maximal amount of protein produced is estimated to be 60 $100 \mathrm{~g} / \mathrm{L}$ of culture broth. ${ }^{11)}$ However, compared to its cellulolytic activity, its xylanolytic activity is not necessarily sufficient for the digestion of lignocellulosic rice straw. ${ }^{89912)}$ In order to enhance the xylanase activity of ATCC66589, the present study adopted disparity mutagenesis, which allows mutations to arise from increased replication errors in DNA polymerase. Due to a lack of proof-reading by DNA polymerase delta, the mutations accumulate in the DNA lagging strand with each replication cycle and are subsequently selected on the desired medium. Thus, a novel tar- 
get-oriented mutant may potentially be generated via accelerated evolution. ${ }^{13)}$

Disparity mutagenesis is effective in generating high frequency mutations and producing desirable mutants in Gram-positive and Gram-negative bacteria, yeasts, fungi, plant, and animal cells and even whole animals. ${ }^{14)}$ For example, it was reported to induce a mutation frequency, which is approximately 7-fold higher than that induced by ethyl methanesulfonate mutagenesis in the budding yeast Saccharomyces cerevisiae. ${ }^{15)}$ Its tolerance to $\mathrm{pH}$ and inorganic solvents has reportedly been improved to levels at which the parent strain is unable to survive. ${ }^{14)}$ We previously reported that glucose-catabolite repression of cellulase production was significantly reduced via this method using T. reesei. ${ }^{16)}$ However, detailed studies on the enhancement of xylanolytic activity of $T$. reesei are lacking. Therefore, the objective of the current study was to analyze the efficacy of disparity mutagenesis in modifying $T$. reesei ATCC66589. Here, we report the isolation and characterization of mutants that produced xylanolytic enzymes at a much higher level than T. reesei ATCC66589, when generated via disparity mutagenesis in a xylan-containing medium.

\section{MATERIALS AND METHODS}

Strain and culture. Trichoderma reesei ATCC66589 purchased from the American Type Culture Collection (ATCC, Manassas, VA, USA) was used throughout the experiment. T. reesei ATCC66589 and its recombinant transformants were inoculated via V8 agar slants onto MM plates (minimal media composed of $5 \mathrm{mg} / \mathrm{mL}$ carboxymethyl cellulose (CMC), $5 \mathrm{mg} / \mathrm{mL}\left(\mathrm{NH}_{4}\right)_{2} \mathrm{SO}_{4}, 15 \mathrm{mg} / \mathrm{mL} \quad \mathrm{KH}_{2} \mathrm{PO}_{4}, 600$ $\mu \mathrm{g} / \mathrm{mL} \mathrm{MgSO}_{4}, 600 \mu \mathrm{g} / \mathrm{mL} \mathrm{CaCl}_{2}, 5 \mu \mathrm{g} / \mathrm{mL} \mathrm{FeSO} \cdot 7 \mathrm{H}_{2} \mathrm{O}$, $1.6 \mu \mathrm{g} / \mathrm{mL} \mathrm{MnSO}_{4} \cdot \mathrm{H}_{2} \mathrm{O}, 1.4 \mu \mathrm{g} / \mathrm{mL} \mathrm{ZnSO}_{4} \cdot 7 \mathrm{H}_{2} \mathrm{O}$, and 2 $\mu \mathrm{g} / \mathrm{mL} \mathrm{CoCl}_{2}$ ) and cultured at $30{ }^{\circ} \mathrm{C}$ for 3 days until spores grew sufficiently. After mixing with $2 \mathrm{~mL}$ saline $(0.7 \%$ $\mathrm{NaCl}, 10 \%$ glycerol in distilled water), spore suspensions were stored at $-80{ }^{\circ} \mathrm{C}$ for further use. Next, $50 \mathrm{~mL}$ of each suspension, diluted to $1 \times 10^{-3}$ or $1 \times 10^{-4}$ spores, was streaked on potato dextrose agar (PDA) plates, and incubated for $48 \mathrm{~h}$.

Chemical reagents. Hygromycin $\mathrm{B}, p$-nitrophenyl $\beta$-Dlactopyranoside ( $p$ NP-lactoside), $p$-nitrophenyl $\beta$-D-xylopyranoside ( $p$ NP-xyloside), xylobiose, and xylan from beechwood were purchased from Sigma-Aldrich Co. (St. Louis, MO, USA). CMC was purchased from Nacalai Tesque Inc. (Kyoto, Japan). Restriction enzymes were obtained from TOYOBO Co., Ltd. (Osaka, Japan). Avicel was purchased from Fluka Chemie Ag (Buchs, Switzerland). All other reagents were obtained from WAKO Pure Chemicals Industries, Ltd. (Osaka, Japan).

Preparation of xylan from birch wood. Ten grams of birch wood chips were sequentially Soxhlet-extracted with $700 \mathrm{~mL}$ methanol for $6 \mathrm{~h}$ to remove oily materials and airdried at room temperature. Ten grams of the obtained powder was refined with $100 \mathrm{~mL}$ distilled water at $65{ }^{\circ} \mathrm{C}$ for 10 $\mathrm{h}$ in a water bath. The residue was collected through vacuum filtration, washed with acetone, and air-dried to obtain dry material. Xylan was extracted from $2.5 \mathrm{~g}$ of the dry material by using $100 \mathrm{~mL}$ of $10 \% \mathrm{KOH}$ with gentle stirring for $2 \mathrm{~h}$ at room temperature under a nitrogen atmosphere to avoid polysaccharide peeling, followed by filtering the solution by using an aspirating Buchner funnel. Following neutralization with $2 \mathrm{M}$ acetic acid, the extract was dialyzed against distilled water in a Visking tube (Viskase Companies, Inc., Lombard, IL, USA) until the electroconductivity decreased to lower than $1.0 \mathrm{mS} / \mathrm{cm}$, and finally freeze-dried.

Plasmid construction and transformation. Construction of plasmids harboring DNA polymerase $\delta$ lacking proofreading activity and their subsequent transformation were performed according to methods previously reported. ${ }^{16)}$ Briefly, the nucleotide sequence of the DNA polymerase $\delta$ was amplified, modified by adding deoxyadenine triphosphate and ligated into the pGEM T-easy vector (Promega Co., Madison, WI, USA; pTA-DPD). The plasmid with DNA polymerase $\delta$ lacking proofreading activity (pTA$m u t \mathrm{DPD})$ was constructed by site-directed mutagenesis using a pTA-DPD template. The pTA-mutDPD was digested with NotI and inserted into pAH digested with the same enzyme. The resulting plasmid was designated pAH-mutDPD.

Plasmid DNA (pAH-mutDPD or pAH; $20 \mu \mathrm{g}$ ) was mixed with $200 \mu \mathrm{L}$ of protoplast suspension prepared from mycelia of $T$. reese $i$ via Yatalase digestion (Takara Bio Inc., Shiga, Japan). To this, $50 \mu \mathrm{L}$ of PEG buffer [10 mM Tris$\mathrm{HCl}(\mathrm{pH} 7.5), 50 \mathrm{mM} \mathrm{CaCl}_{2}$, and $25 \%$ polyethylene glycol 6000] was added, and the mixture was incubated in an ice bath for $20 \mathrm{~min}$. Incubation was further continued at $25^{\circ} \mathrm{C}$ for $5 \mathrm{~min}$ after adding $2 \mathrm{~mL}$ PEG buffer. Following the addition of $4 \mathrm{~mL}$ of Buffer C [10 mM Tris- $\mathrm{HCl}$ ( $\mathrm{pH} 7.5), 10$ $\mathrm{mM} \mathrm{CaCl}_{2}$, and $1.0 \mathrm{M}$ sorbitol], the transformants were collected and plated on $1.2 \%$ agar overlaid onto MM plates with $200 \mu \mathrm{g} / \mathrm{mL}$ of hygromycin B. The plates were then incubated in the dark for 7 days at $30{ }^{\circ} \mathrm{C}$.

Selection and curing of mutants. Spores $\left(1 \times 10^{3}\right)$ of transformants propagated in a V8 slant were plated on MM agar plates containing $5 \mathrm{~g} / \mathrm{L}$ of xylan prepared from birch wood as the single carbon source instead of glucose and incubated at $30^{\circ} \mathrm{C}$. Colonies grown on the plate were picked after 5 days of incubation. Mutant strains thus obtained were transferred to PDA plates with nutrient-rich medium and cured for several days to delete plasmids harboring AH-mutDPD. Deletion of plasmid DNA was assessed by growth on PDA plates containing $200 \mu \mathrm{g} / \mathrm{mL}$ hygromycin B.

Scanning Electron Microscopy. Mycelia of T. reesei grown for 1 month or longer were soaked in $2 \%$ glutaraldehyde solution, washed thrice with $0.1 \mathrm{M}$ cacodylate buffer (pH 7.2) and suspended in $1 \%$ osmium solution. Following stepwise dehydration of $10 \mathrm{~min}$ each in 50, 70, 80, 90 , and $100 \%$ acetone; the mycelia were further dehydrated twice in $100 \%$ acetone for $30 \mathrm{~min}$ each. The dehydrated sample was immersed in a 1:1 mixture of acetone and isoamyl acetate for $30 \mathrm{~min}$ and then in $100 \%$ isoamyl acetate for $90 \mathrm{~min}$, prior to being stored at $4{ }^{\circ} \mathrm{C}$. For the final preparation step, the mycelia were dried using a critical point drier (HCP-2, Hitachi High-Tech Co., Tokyo, Japan) 
and observed under a scanning electron microscope (S-3500N, Hitachi High-Tech Co.) after vacuum deposition.

Cultivation for enzyme production. Spore suspensions (1 $\times 10^{7} / 100 \mu \mathrm{L}$ ) of parent or selected mutants were inoculated into $100 \mathrm{~mL}$ pre-culture medium composed of $3 \%$ glucose, $0.6 \%$ corn steep liquor (Sigma-Aldrich), $0.6 \%$ ammonium sulfate, and $0.1 \%$ TritonX-100 (Sigma-Aldrich) in a $500 \mathrm{~mL}$ shaker flask and cultured for 3 days at $30{ }^{\circ} \mathrm{C}$ and $200 \mathrm{rpm}$. For xylan-degrading enzyme production, approximately $10 \%$ of the seed culture was added to $50 \mathrm{~mL}$ medium consisting of $0.5 \%$ xylan, $0.1 \%$ corn steep liquor, $0.1 \%$ ammonium sulfate and cultured at $30{ }^{\circ} \mathrm{C}$ for 3 days. To produce cellulose-degrading enzyme, approximately $10 \%$ of seed culture was added to $50 \mathrm{~mL}$ medium consisting of $2 \%$ Avicel, $0.4 \%$ corn steep liquor, and $0.4 \%$ ammonium sulfate, and cultivated at $30{ }^{\circ} \mathrm{C}$ for 5 days. The $\mathrm{pH}$ of the culture fluid was adjusted to 5.0 with $10 \%$ ammonium hydroxide and $10 \% \mathrm{HCl}$ throughout cultivation. At 24 $\mathrm{h}$ intervals, $500 \mu \mathrm{L}$ culture broth was collected in a $1.5 \mathrm{~mL}$ sample tube and used for enzyme analyses.

Assays of enzyme activity. The activities of xylanase and carboxymethyl cellulase (CMCase) were assayed using a reaction mixture consisting of $1 \%$ xylan from beechwood or CMC, $25 \mu \mathrm{L}$ of $500 \mathrm{mM}$ phosphate buffer (pH 6.0) and $25 \mu \mathrm{L}$ of enzyme solution, amounting to a total volume of $250 \mu \mathrm{L}$. Following incubation at $50{ }^{\circ} \mathrm{C}$ for $30 \mathrm{~min}, 100 \mu \mathrm{L}$ of the reaction solution was mixed with $300 \mu \mathrm{L}$ of dinitrosalicylic acid (DNS) reagent, heated for $5 \mathrm{~min}$ in a boiling water bath to stop the reaction, and cooled down under running tap water to ambient temperature. A fifty microliters aliquot was diluted with $950 \mu \mathrm{L}$ of distilled water and colorimetrically assayed at $500 \mathrm{~nm}$ using a spectrophotometer (Beckman Coulter, Inc., Brea, CA, USA). ${ }^{17)}$ One unit of xylanase and CMCase activities were defined as the amount of the enzyme that liberates $1 \mu \mathrm{mol}$ of reducing value calibrated with xylose and glucose per minute, respectively.

The $\beta$-xylosidase activity and $p$ NP-lactoside hydrolyzing ( $p$ NP-lactosidase) activity was assayed using a reaction mixture composed of $100 \mu \mathrm{L}$ of $4 \mathrm{mM} p \mathrm{NP}$-xyloside or $p$ NP-lactoside, $100 \mu \mathrm{L}$ of $200 \mathrm{mM}$ phosphate buffer ( $\mathrm{pH}$ 6.0) and $200 \mu \mathrm{L}$ of enzyme solution, amounting to a total volume of $400 \mu \mathrm{L}$. Following incubation at $50{ }^{\circ} \mathrm{C}$ for 30 min, $400 \mu \mathrm{L}$ of $1 \mathrm{M}$ sodium carbonate was added to the reaction mixture, which was colorimetrically assayed at 415 nm using a spectrophotometer (iMark Microplate Reader, Bio-Rad Laboratories Inc., Hercules, CA, USA). ${ }^{17)}$ One unit of activity was defined as the amount of enzyme that liberates $1 \mu \mathrm{mol}$ of $p$-nitrophenol per minute.

Induction assay on xylanase activity. A five milliliters pre-culture of $1 \times 10^{7}$ spores was transferred to $50 \mathrm{~mL}$ culture medium containing each of $0.1 \%$ xylan component sugar (xylobiose, D-glucuronic acid, L-arabinose, D-xylose), related polyol (xylitol) or cellulase inductive sugar (L-sorbose, lactose, D-galactose), and $2 \%$ Avicel. Following incubation at $30{ }^{\circ} \mathrm{C}$ at $200 \mathrm{rpm}$ for $3 \mathrm{~d}$, the broth supernatant was sampled every day and subjected to xylanase activity assays.

\section{RESULTS}

\section{Selection of the mutant strain and its morphology.}

Trichoderma reesei ATCC66589 transformants (pBluescript $2 \mathrm{SK}+/ \mathrm{AH}+$ mutDPD inserted) were subcultured in triplicate (for stabilization of colonial phenotypes) on selection medium plates containing xylan as a single carbon source to enhance xylan-degrading enzyme inducibility. Subsequently, spores were inoculated on agar plates consisting of the same medium and incubated at $30{ }^{\circ} \mathrm{C}$ for several days. From the spores that colonized within 5 days, four strains were selected and arbitrarily named as XM1, XM2, XM3, and XM4. Colony sizes of the mutants were mostly the same as those of the parent grown on glucose, xylose, and PDA plates (Fig. 1). However, sporulation of the mutant colonies was more luxuriant than that for parental colonies in all plates examined.

Scanning electron micrographs of parent and mutant XM1 strains grown on PDA are shown in Fig. 2. The spores of the parental strain were smooth-surfaced spheres (Fig. 2A), whereas the spore of the mutant XM1 strain were spheres with small-humped surfaces (Fig. 2B). All other mutant strains (XM2, XM3, and XM4) had the same appearance as XM1 (data not shown).

\section{Productivity of enzymes.}

Xylan-hydrolyzing (xylanase) and $p$ NP-xyloside hydrolyzing ( $\beta$-xylosidase) activities of the parent and mutant XM1 strains grown in xylan-containing media are shown in Fig. 3. In the parental strain, xylanase activity and $\beta$-xylosidase activity were not clearly detected even after 2 days (Fig. 3A). On the other hand, xylanase activity in the mutant strain was detected after $24 \mathrm{~h}$, and after 3 days this activity was 15.8 -fold higher than that of the parental strain (Fig. 3A). $\beta$-xylosidase activity in XM1 strain was not detected even after $24 \mathrm{~h}$, whereas after 3 days this activity was 11.0-fold higher than that of the parental strain (Fig. 3B). The other three mutants XM2, XM3, and XM4 showed similar profiles for the xylanase and $\beta$-xylosidase activities.

Contrary to this, when cultivated in a medium containing Avicel as the sole carbon source, xylanase activity, $\beta$-xylosidase activity, CMCase activity, and $p$ NP-lactosidase activity of the mutant were 0.14-, 0.33-, 0.21-, and 0.08-fold compared to the parental strain after 5 days, respectively (Fig. 4). No lag time was seen in activity expression between the mutant and parental strains.

\section{Effect of xylan component sugars and related polyol, and cellulase inductive sugars on the xylanase activity.}

The inductive effect of component sugars and related compounds on xylanase activity was examined. The parent and mutant strains were cultivated in Avicel media, each containing D-xylose, xylobiose, L-arabinose, glucuronate, and xylitol as a potent inducer. During the initial $24 \mathrm{~h}$, xylanase activity was found in the mutant strain supplemented with D-xylose and xylobiose, whereas no activity was found in the parent strain (Figs. 5A and B). Thereafter, the activity of the parent strain increased rapidly during a 3-day 


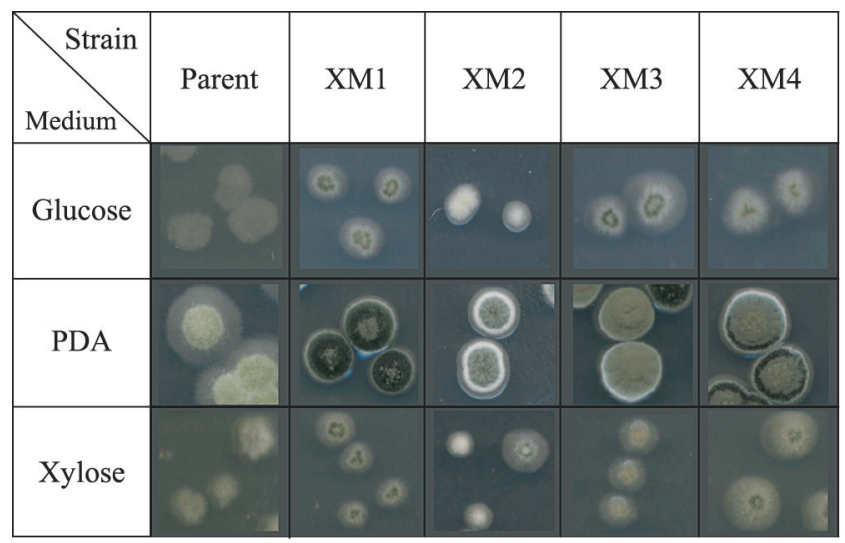

Fig. 1. Colonies of parent and mutant strains on agar plates.

The spores $\left(1 \times 10^{2}\right)$ of parent and mutant strains (XM1, XM2, $\mathrm{XM} 3$, and XM4) were plated on glucose agar, PDA, or xylan agar plates. Following incubation for 5 days at $30^{\circ} \mathrm{C}$, the propagated colonies were observed with an image scanner (EPSON GT-9700F).
A

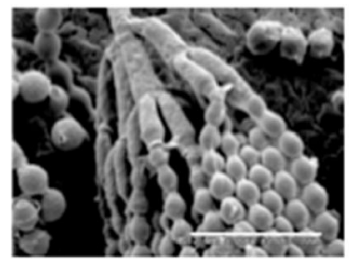

$\mathrm{B}$

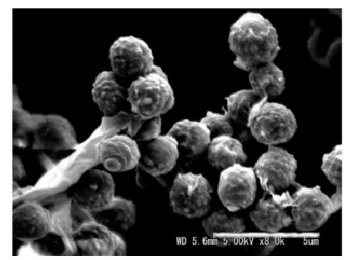

Fig. 2. Scanning electron microscopy of parent and mutant XM1 strains.

After growing at $30^{\circ} \mathrm{C}$ for 3 days on PDA, conidiospores propagated were observed under a scanning electron microscope, S-3500 (Hitachi High-Technologies Corporation). A, parent; B, XM1 mutant; scale bar indicates $5 \mu \mathrm{m}$.
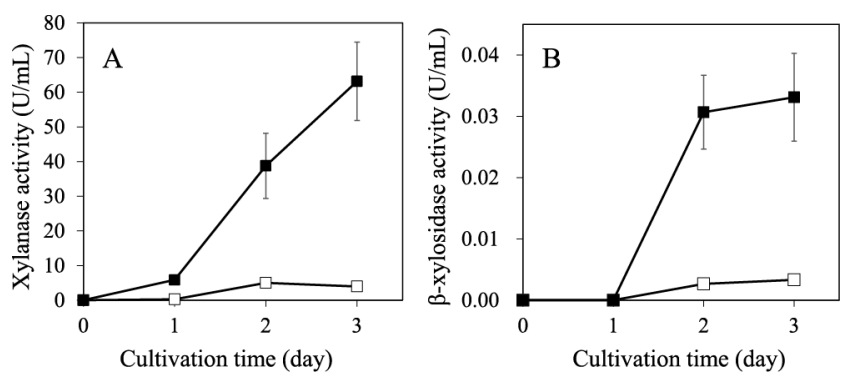

Fig. 3. Xylanase and $\beta$-xylosidase activities of parent and mutant XM1 strains grown in xylan-containing media.

Xylanase (A) and $\beta$-xylosidase (B) activities of parent and mutant XM1 strains grown in xylan-containing media. The strains were cultivated at $30{ }^{\circ} \mathrm{C}$ and $200 \mathrm{rpm}$ for 3 days on xylan as a sole carbon source. Parent, open squares; XM1, closed squares. The data were obtained from three independent experiments. The error bars indicate the standard deviation of three independent replicates.

cultivation. Among the sugars examined, D-xylose and Larabinose showed a significant enhancing effect on the xylanase activity. However, the activity expression profile of the mutant strain was markedly different from that of the parent. Except for the addition of xylobiose, the activity of the mutant strain was obviously lower than that of the parent strain after 3 days. In the case of D-xylose, the activity specifically increased during the initial $24 \mathrm{~h}$ and then decreased (Fig. 5B).

The inductive effects of L-sorbose, lactose, and galac-
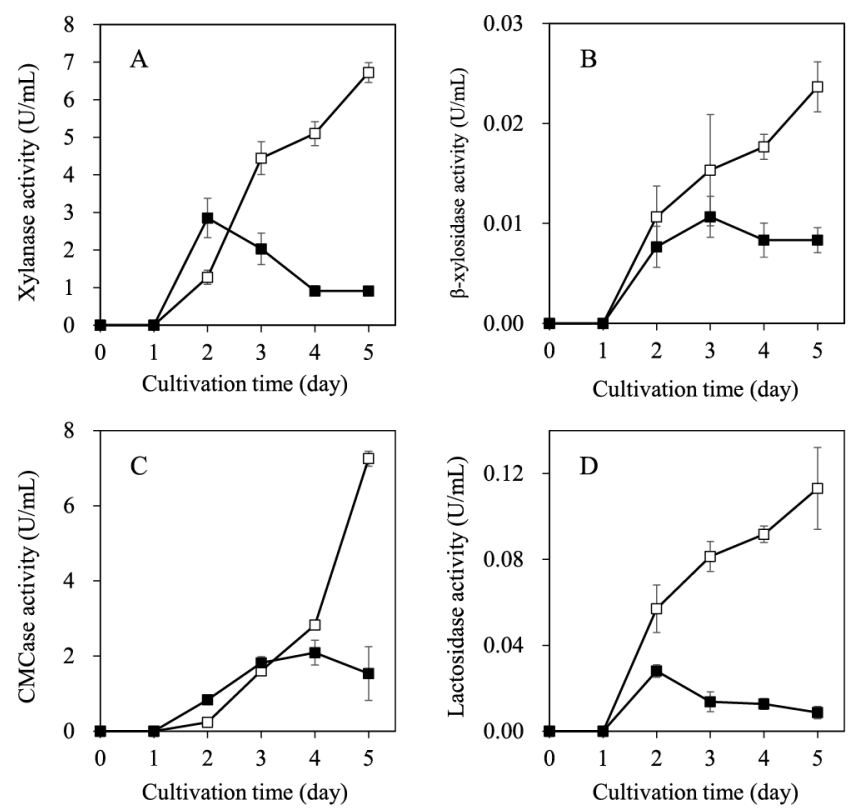

Fig. 4. Xylanolytic and cellulolytic activities of parental and mutant XM1 strains grown in Avicel-containing media.

Xylanase (A), $\beta$-xylosidase (B), CMCase (C), and $p$ NP-lactosidase (D) activities of parent and mutant XM1 strains grown in Avicel-containing media. The strains were cultivated at $30{ }^{\circ} \mathrm{C}$ and $200 \mathrm{rpm}$ for 5 days on Avicel as a sole carbon source. Parent, open squares; mutant XM1, closed squares. The data were obtained from three independent experiments. The error bars indicate the standard deviation of independent replicates.
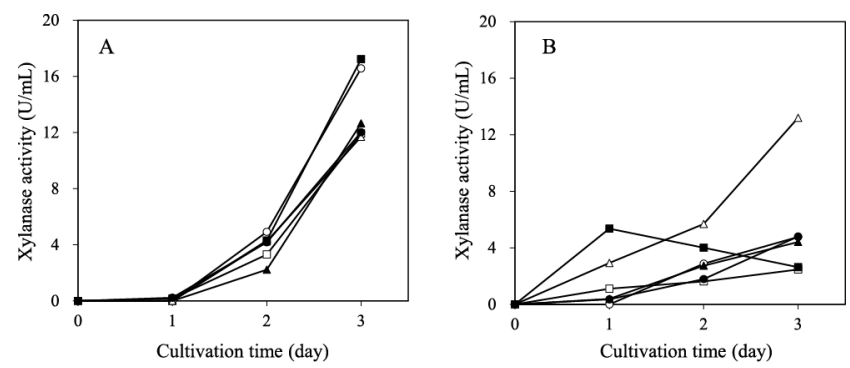

Fig. 5. Effect of xylan component sugars or related polyols on xylanase activities of parental and mutant XM1 strains.

Xylanase activities of parent (A) and mutant XM1 (B) strains grown on the medium containing $0.1 \%$ xylan component sugar or related polyol and $2 \%$ Avicel. The strains were cultivated at $30^{\circ} \mathrm{C}$ and $200 \mathrm{rpm}$ for 3 days. Control, open squares; xylitol, closed triangles; xylobiose, open triangles; D-glucuronic acid, closed circles; L-arabinose, open circles; D-xylose, closed squares. The data represents the average value of two independent replicates.

tose, known as cellulase inducers, on xylanase activity are shown in Fig. 6. L-Sorbose and D-galactose showed little influence on the hydrolyzing activity of the parent, while they caused a slight increase in xylanase activity of the mutant. Lactose showed a slight decrease in the hydrolyzing activity of the parent, while it caused an increase in xylanase activity of the mutant.

\section{DISCUSSION}

Enhancement of hemicellulase is considered to be critical for enzymatic digestion of lignocellulosic materials using the $T$. reesei enzyme preparation. Therefore, we tried to generate the mutant of $T$. reesei ATCC66589 with high xy- 

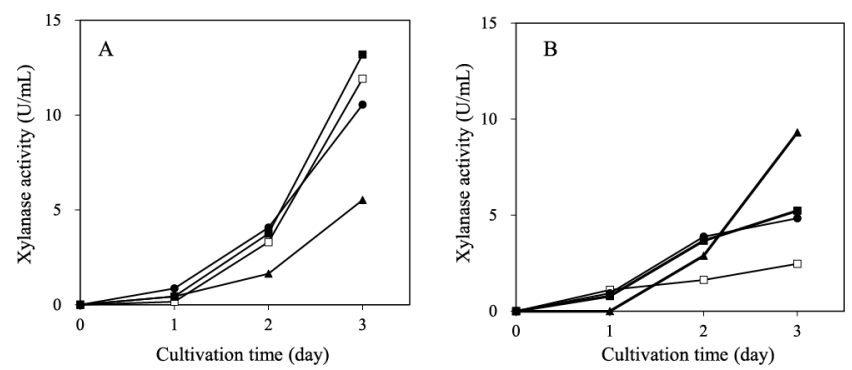

Fig. 6. Effect of cellulase inductive sugars on xylanase activities of parental and mutant XM1 strains.

Xylanase activities of parent (A) and mutant XM1 (B) strains grown on the medium containing $0.1 \%$ cellulase inductive sugar and $2 \%$ Avicel. The strains were cultivated at $30{ }^{\circ} \mathrm{C}$ and $200 \mathrm{rpm}$ for 3 days. Control, open squares; L-sorbose, closed circles; lactose, closed triangles; D-galactose, closed squares. The data represents the average value of two independent replicates.

lanase activity using disparity mutagenesis and successive selection in the medium containing white birch xylan as a simple carbon source. One of the mutants obtained, XM1, showed 15.8-fold higher xylanase activity and 11.0-fold higher $\beta$-xylosidase activity compared to those of the parent strain when cultivated in xylan-containing media (Fig. 3 ). In contrast, xylanolytic activities were significantly lowered 0.14 -fold for xylanase and 0.33 -fold for $\beta$-xylosidase, when cultivated in the Avicel medium.

Xylanase activities of $T$. reesei Rut C-30 and $T$. reesei QM9414 were reportedly derived from xylanase 1, 2, 3 (XYN1, 2, 3), and $\beta$-xylosidase (BXL). ${ }^{18) 19) 20)}$ Similarly, xylanolytic activities of the XM1 mutant have probably been derived from these xylanases XYN1, 2, 3 and $\beta$-xylosidase BXL. However, the enhanced profile of xylanolytic activities was substantially different between the parent and the mutant as previously mentioned. Considering these results, the induction mechanism of xylanolytic enzymes seems somewhat modified in the mutant strain of $T$. reesei ATCC66589 generated by disparity mutagenesis.

Regarding the parental strain, D-xylose and L-arabinose showed a significant enhancing effect on xylanase activity (Fig. 5A). Reportedly, T. reesei QM9414 xylanase is induced by $\mathrm{D}$-xylose and L-arabinose via separate induction pathways. ${ }^{2122)} \mathrm{D}$-xylose is well-known to be reduced to xylitol by D-xylose/aldose reductase (XYL1) and successively oxidized to D-xylulose by xylitol dehydrogenase (XDH1) or L-arabitol dehydrogenase (LAD1). ${ }^{22)}$ L-arabinose is also changed to L-xylulose by XYL1 and LAD1. ${ }^{21)}$ However, the xylanase activity of the mutant strain was enhanced by $\mathrm{D}$-xylose and not by L-arabinose. Hence, in this case, an unknown factor might supplement XYL1 function, or XYL1 is not essential for xylanase induction as seen in the lad1-xdh1 double deletion strain of $T$. reesei QM9414. ${ }^{21) 22}$ Although the detailed mechanism is not known, these results suggest that the path from D-xylitol to xylulose was in some way modified by the mutation.

L-Sorbose, lactose, and galactose ${ }^{823) 24) 25)}$ significantly stimulated xylanase induction in the mutant (Fig. 6B). LSorbose is well-known as a xylanase inducer in $T$. reesei ATCC66589 ${ }^{26)}$ and our study was consistent with the results described in this report. The xylanase XYN3, different from the other xylanases $(\mathrm{XYN} 1,2)$, was reportedly induced synchronously with cellulase induction in $T$. reesei ATCC66589. ${ }^{27)}$ However, as it is not known whether the XM1 mutant may produce XYN3, this issue needs to be addressed.

In conclusion, we utilized disparity mutagenesis to generate a mutant of $T$. reesei ATCC66589. One of the mutant strains, XM1 was able to produce xylanolytic enzymes at a much higher level than that of the parental strain when cultivated in xylan-containing media. The xylanolytic and cellulolytic activities of the mutant were lower than that of the parental strain when cultivated in Avicel-containing media. The XM1 mutant alone might not be enough for the degradation of biomass consisting of xylan-rich polysaccharides like rice straw. Hence, we suggest applying the XM1 mutant in combination with another strain like ATCC66589 for processing the biomass degradation. Xylanase is an enzyme, which is frequently used in various applications related to feed, bread baking, beverages, and pharmaceuticals. ${ }^{2829) 30}$ ) The causes underlying the peculiar characteristics of the mutant strain remain unclear and are currently being studied. The availability of the $T$. reesei genome as well as tools such as Next-Generation Sequencer and RNAseq may provide further insight into the functioning of these mutants.

\section{COMPLIANCE WITH ETHICAL STANDARDS}

Funding: This study was partly supported by a grant from the Biomass Utilization Project of Ministry of Agriculture, Forestry, and Fisheries of Japan (BEC-C070).

Conflict of Interest: All authors have no potential of conflict.

Ethical approval: This article does not contain any studies with human participants or animals performed by any of the authors.

\section{ACKNOWLEDGMENTS}

This study was partly supported by a grant from the Biomass Utilization Project of MAFF, Japan (BEC-C070).

\section{REFERENCES}

1) A.S. Liggenstoffer, N.H. Youssef, M.R. Wilkins, and M.S. Elshahed: Evaluating the utility of hydrothermolysis pretreatment approaches in enhancing lignocellulosic biomass degradation by the anaerobic fungus Orpinomyces sp. strain C1A. J. Microbiol. Methods, 104, 43-48 (2014).

2) J.Y. Park, M. Arakane, R. Shiroma, M. Ike, and K. Tokuyasu: Culm in rice straw as a new source for sugar recovery via enzymatic saccharification. Biosci. Biotechnol. Biochem., 74, 50-55 (2010).

3) Y. Feng, X. Qi, H.L. Jian, R.C. Sun, and J.X. Jiang: Effect of inhibitors on enzymatic hydrolysis and simultaneous saccharification fermentation for lactic acid production from steam explosion pretreated Lespedeza stalks. BioResources, 7, 3755-3766 (2012). 
4) P. Kahar, K. Taku, and S. Tanaka: Multiple effects of swelling by sodium bicarbonate after delignification on enzymatic saccharification of rice straw. J. Biosci. Bioeng., 116, 725-733 (2013).

5) S.D. Mansfield, C. Mooney, and J.N. Saddler: Substrates and enzyme characteristics that limit cellulose hydrolysis. Biotechnol. Prog., 15, 804-816 (1999).

6) D. Martinez, R.M. Berka, B. Henrissat, M. Saloheimo, M. Arvas, S.E. Baker, J. Chapman, O. Chertkov, P.M. Coutinho, D. Cullen, E.G. Danchin, I.V. Grigoriev, P. Harris, M. Jackson, C.P. Kubicek, C.S. Han, I. Ho, L.F. Larrondo, A.L. de Leon, J.K. Magnuson, S. Merino, M. Misra, B. Nelson, N. Putnam, B. Robbertse, A.A. Salamov, M. Schmoll, A. Terry, N. Thayer, A. Westerholm-Parvinen, C.L. Schoch, J. Yao, R. Barabote, M.A. Nelson, C. Detter, D. Bruce, C.R. Kuske, G. Xie, P. Richardson, D.S. Rokhsar, S.M. Lucas, E.M. Rubin, N. Dunn-Coleman, M. Ward, and T.S. Brettin: Genome sequencing and analysis of the biomass-degrading fungus Trichoderma reesei (syn. Hypocrea jecorina). Nat. Biotechnol., 26, 533-560 (2008).

7) E.T. Reese: History of the cellulase program at the U.S. army Natick Development Center. Biotechnol. Bioeng. Symp., 6, 9-20 (1976).

8) M. Kawamori, Y. Morikawa, and S. Takasawa: Induction and production of cellulases by L-sorbose in Trichoderma reesei. Appl. Microbiol. Biotechnol., 24, 449-453 (1986).

9) B.S. Montenecourt and D.E. Eveleigh: Preparation of mutants of Trichoderma reesei with enhanced cellulase production. Appl. Environ. Microbiol., 34, 777-782 (1977).

10) V. Seidl and B. Seiboth: Trichoderma reesei: Genetic approaches to improving strain efficiency. Biofuels, 1, 343354 (2010).

11) J.R. Cherry and A.L. Findantsef: Directed evolution of industrial enzymes: an update. Curr. Opin. Biotechnol., 14, 438-443 (2003).

12) Y. Morikawa, M. Kawamori, Y. Ado, Y. Shinsha, F. Oda, and S. Takasawa: Improvement of cellulase production in Trichoderma reesei. Agric. Biol. Chem., 49, 1869-1871 (1985).

13) M. Furusawa and H. Doi: Asymmetrical DNA replication promotes evolution: disparity theory of evolution. Genetica, 102-103, 333-347 (1998).

14) S. Yano: Breeding of yeasts for industrial use by disparity mutagenesis. Seibutsu-kogaku Kaishi, 89, 524-526 (2011) (in Japanese).

15) Y. Shiwa, S. Fukushima-Tanaka, K. Kasahara, T. Horiuchi, and $\mathrm{H}$. Yoshikawa: Whole-genome profiling of a novel mutagenesis technique using proofreading-deficient DNA polymerase $\delta$. Int. J. Evol. Biol., 2012, Article ID 860797, $1-8$ (2012).

16) H. Iwakuma, Y. Koyama, A. Miyachi, M. Nasukawa, H. Matsumoto, S. Yano, J. Ogihara, and T. Kasumi: Generation of a glucose de-repressed mutant of Trichoderma reesei using disparity mutagenesis. Biosci. Biotechnol. Biochem., 80, 486-492 (2016).

17) G.L. Miller: Use of dinitrosalicylic acid reagent for determination of reducing sugar. Anal. Chem., 31, 426-428 (1958).
18) M. Tenkanen, J. Puls, and K. Poutanen: Two major xylanases of Trichoderma reesei. Enzyme Microb. Technol., 14, 566-574 (1992).

19) A. Törrönen, R.L. Mach, R. Messner, R. Gonzalez, N. Kalkkinen, A. Harkki, and C.P. Kubicek: The two major xylanases from Trichoderma reesei: characterization of both enzymes and genes. Biotechnology (NY). 10, 14611465 (1992).

20) S. Zeilinger, R.L. Mach, M. Schindler, P. Herzog, and C.P. Kubicek: Different inducibility of expression of the two xylanase genes xyn 1 and xyn 2 in Trichoderma reesei. $J$. Biol. Chem., 271, 25624-25629 (1996).

21) A.R. Mach-Aigner, L. Gudynaite-Savitch, and R.L. Mach: L-Arabitol is the actual inducer of xylanase expression in Hypocrea jecorina (Trichoderma reesei). Appl Environ. Microbiol., 77, 5988-5994 (2011).

22) H. Silvia, B. Robert, M. Benjamin, S. Bernhard, and P.K. Christian: Xylanase gene transcription in Trichoderma reesei is triggered by different hemicellulosic pentose polymers. Eukaryot. Cell, 12, 390-398 (2013).

23) P.K. Foreman, D. Brown, L. Dankmeyer, R. Dean, S. Diener, N.S. Dunn-Coleman, F. Goedegebuur, T.D. Houfek, G.J. England, A.S. Kelly, H.J. Meerman, T. Mitchell, C. Mitchinson, H.A. Olivares, P.J. Teunissen, J. Yao, and M. Ward: Transcriptional regulation of biomass-degrading enzymes in the filamentous fungus Trichoderma reesei. J. Biol. Chem., 278, 31988-31997 (2003).

24) C.P. Kubicek, M. Mikus, A. Schuster, M. Schmoll, and B. Seiboth: Metabolic engineering strategies for the improvement of cellulase production by Hypocrea jecorina. Biotechnol. Biofuels, 2, 19 (2009).

25) B. Seiboth, C. Gamauf, M. Pail, L. Hartl, and C.P. Kubicek: The D-Xylose reductase of Hypocrea jecorina is the major aldose reductase in pentose and D-galactose catabolism and necessary for $\beta$-galactosidase and cellulase induction by lactose. Mol. Microbiol., 66, 890-900 (2007).

26) J. Xu, M. Nogawa, H. Okada, and Y. Morikawa: Xylanase induction by L-sorbose in a fungus, Trichoderma reesei PC-3-7. Biosci. Biotechnol. Biochem., 62, 1555-1559 (1998).

27) J. Xu, M. Nogawa, H. Okada, and Y. Morikawa: Regulation of xyn3 gene expression in Trichoderma reesei PC-3-7. Appl. Microbiol. Biotechnol., 54, 370-375 (2000).

28) G. Dervilly, C. Leclercq, D. Zimmerman, C. Roue, J.F. Thibault, and L. Sauliner: Isolation and characterization of high molecular mass water-soluble arabinoxylans from barley malt. Carbohydr. Polym., 47, 143-149 (2002).

29) J.C. Parajó, H. Domínguez, and J.M. Domínguez: Biotechnological production of xylitol. Part 1: interest of xylitol and fundamentals of its biosynthesis. Bioresour. Technol., 65, 191-201 (1998).

30) L.N. Twomey, J.R. Pluske, J.B. Rowe, M. Choct, W. Brown, M.F. McConnell, and D.W. Pethick: The effects of increasing levels of soluble non-starch polysaccharides and inclusion of feed enzymes in dog diets on faecal quality and digestibility. Anim. Feed Sci. Technol., 108, 71-82 (2003). 